\title{
A case of high risk modified radical mastectomy with Ischemic heart disease and beauty of regional blocks
}

\author{
Neeraj Mahajan ${ }^{1 *}$, Suchita Joshi ${ }^{2}$, Ankita Patil $^{3}$ \\ 1,2,3 Department of Anaesthesia \& Critical Care Medicine, Government Medical College, Aurangabad, Maharashtra, INDIA. \\ Email: neerajmahajan456@gmail.com
}

Abstract Background: Breast carcinoma incidence has seen a rising trend these days. Modified Radical Mastectomy(MRM) are done under General anaesthesia. However, anaesthesia specialists are showing more interest towards regional anaesthesia for MRM surgeries along with General anaesthesia for better intraoperative hemodynamic stability, less intraoperative and postoperative opioids(thus avoiding polypharmacy) and also fewer postoperative complications. Hence we advocated General anaesthesia plus landmark guided Pectoralis major 1 block(PEC1) and Serratus anterior plane block(SAPB) as the anaesthesia technique of choice in this patient.

Key Word: MRM, SAPB, PEC1, IHD, DEXAMETHASONE, PONV(postoperative nausea and vomiting), RESCUE ANALGESIA, VAS(Visual analogue score).

\section{*Address for Correspondence:}

Dr Neeraj Mahajan, Department of Anaesthesia \& Critical Care Medicine, Government Medical College, Aurangabad, Maharashtra, INDIA. Email: neerajmahajan456@gmail.com

Received Date: 21/04/2020 Revised Date: 12/05/2020 Accepted Date: 05/06/2020

DOI: https://doi.org/10.26611/10151511

This work is licensed under a Creative Commons Attribution-NonCommercial 4.0 International License. (cc) E EY-NC

\begin{tabular}{|l|l|}
\hline \multicolumn{2}{|c|}{ Access this article online } \\
\hline Quick Response Code: & Website: \\
\hline & www.medpulse.in \\
& \\
\hline
\end{tabular}

\section{INTRODUCTION}

A 45 yr old female with known case of Ischemic heart disease diagnosed 2 months back and was started on tablet aspirin 150 $\mathrm{mg}$ and tab clopidogrel. She was also recently diagnosed hypertensive on tab telmisartan $40 \mathrm{mg}$ od. Patient was diagnosed with Rt breast infiltrating ductal carcinoma and was posted for Modified Radical mastectomy.

Preoperative evaluation: Patient is thin built, conscious, oriented to time, place, person.

Pulse-96/min, BP-150/90 and ECG showed $t$ inversion in v2$\mathrm{v} 6$ and st depression in v2-v6.

$2 \mathrm{~d}$ echo was done which revealed ejection fraction of $60 \%$ and no other abnormality, cardiology opinion was taken and fitness was obtained with high risk consent. Patient was accepted under American Society of Anaesthesiology grading
3 under semi urgent basis and it was advised to continue tab aspirin and stop tab clopidogrel 5 days before the surgery. High risk consent was obtained and adequate blood and blood products were kept ready. On the day of surgery NBM of the patient was confirmed and patient was wheeled inside the operation theatre. Patient was explained about type of anaesthesia, options of analgesia and complications of surgery and anaesthesia.

\section{PLAN OF ANAESTHESIA}

General anaesthesia plus landmark guided Serratus anterior plane block and Pectoralis major 1 block(PEC1). Patient was premedicated with inj midazolam, fentanyl and ondansetron. Patient was induced with inj propofol and succinylcholine and maintained on oxygen plus nitrous oxide plus isoflurane plus vecuronium on controlled ventilation on closed circuit. After administration of General anaesthesia landmark guided Serratus anterior plane block was given with total $20 \mathrm{ml}$ of local anaesthetic(lignocaine with bupivacaine) and Pec1 block was given with $10 \mathrm{ml}$ of local anaesthetic and $4 \mathrm{mg}$ dexamethasone was added. here we avoided adrenaline in lignocaine because patient was a known case of Ischemic heart disease.

Serratus Anterior plane block

Our aim is to deposit the local anaesthetic in the fascial plane deep to serratus anterior muscle and above the rib or external intercostal muscle. $5^{\text {th }}$ rib is identified and traced till the mid axillary line and point of intersection is point of entry of 
needle. Serratus anterior plane block(SAPB) blocks the lateral cutaneous branches of intercostals nerves(t2-t6).

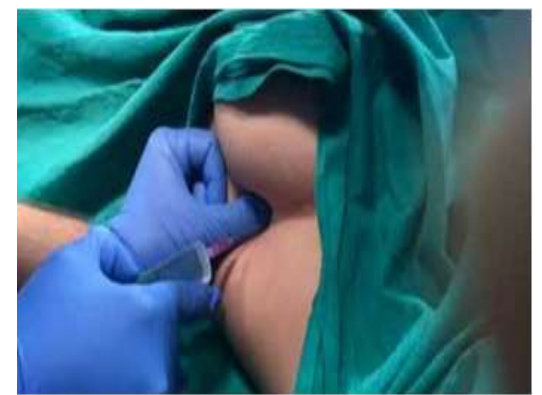

Image 1: Landmark guided Serratus anterior plane block.

Pectoralis major 1 block(PEC1)

Here injection of local anaesthetic is done between pectoralis major and minor at the level of $3^{\text {rd }}$ rib to block the lateral and medial pectoral nerves.

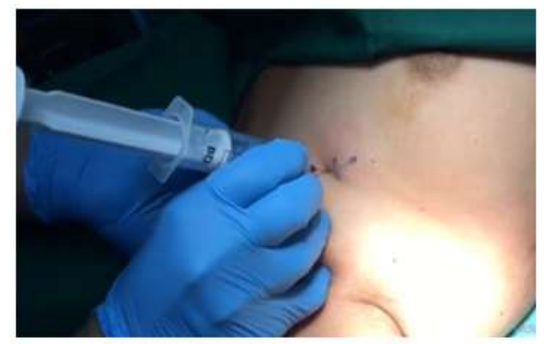

Image 2: Landmark guided Pectoralis major1(PEC1) block.

Intraoperative course and management

Immediately after incision the vitals were rock stable with pulse ranging from $72-73 / \mathrm{min}$ and blood pressure $106 / 80$ to $110 / 76$, there was no surge in pulse or blood pressure which is common after incision.

There was only one episode of bradycardia which was managed with inj glycopyrrolate $(0.2 \mathrm{mg})$ and later heart rate remained stable throughout the procedure. volatile anaesthetic isoflurane was kept at 0.6 MAC as there was decreased requirement and there was no need of opioids. Case lasted for 3 hours and patient was extubated on operating table after meeting all necessary criteria's of extubation(patient was alert, warm comfortable and pain free).

Postoperative course and management

Patient was shifted to Trauma intensive care unit for observation and further management. Patient was comfortable and all standard monitors like ECG, Non-invasive blood pressure and pulse oximetry were attached and oxygen supplementation was provided with facemask at 6 litre/min flow.
Patient was pain free for about 14 hours and was given rescue analgesia in the form of inj paracetamol iv when there was breakthrough pain(when VAS score $>4$ ). All the laboratory investigation which were sent postoperatively were normal and patient was sent to ward 24 hours later and discharged.

\section{DISCUSSION}

Breast surgeries like MRM with underlying co-morbidities of the patient pose a great challenge to the anaesthetist because such surgeries are associated with complications like intense pain, postoperative nausea and vomiting which delays discharge of the patient and increases length of stay and cost of treatment to the patient. Balanced anaesthesia techniques like General anaesthesia with regional blocks like Serratus anterior plane block and PEC1 block provide a stable introperative hemodynamics and decreases need for opioids and provide a relatively bloodless field of dissection(hypotensive anaesthesia) and use of adjuncts like dexamethasone prolongs the analgesia for upto 14 hours postoperatively and decreases likelihood of postoperative nausea and vomiting. So these SAPB and PEC1 blocks by landmark technique are easy to administer with relative safety.

\section{CONCLUSION}

Enhanced recovery after surgery under general anaesthesia is very important to bring back patients physiological and psychological state of body and mind to its normal level. Here we successfully conducted a case of MRM under combined General anaesthesia and regional blocks(SAPB AND PEC1 block) which are components of multimodal opioid sparing analgesia which lead to stable introperative and post operative course without any complications.

\section{REFERENCES}

1. Egyptian Journal of Anaesthesia 25(4):401-411. January 2009

2. Bashandy GM,Abbas DN. Pectoral nerves 1 and 2 blocks in multimodal analgesia for breast cancer surgery:A randomized clinical trial.Reg Anesth Pain Med.2015;40:68-74.

3. Blanco R. The "pecs block: a novel technique for providing analgesia after breast surgery. Anaesthesia. 2011;66(9):847-848.

4. Ohgoshi Y,Yokozuka M, Terajima K. Serratus intercostal plane block for breast surgery. Masui 2015;64:610-614.

5. Madabushi R, Tewari S, Gautam SK, Agarwal A:Serratus anterior plane block:a new analgesic technique for post thoracotomy pain. Pain Physicians2015;18:E421-424.

Source of Support: None Declared
Conflict of Interest: None Declared

Policy for Articles with Open Access:

Authors who publish with MedPulse International Journal of Anesthesiology (Print ISSN:2579-0900) (Online ISSN: 2636-4654) agree to the following terms: Authors retain copyright and grant the journal right of first publication with the work simultaneously licensed under a Creative Commons Attribution License that allows others to share the work with an acknowledgement of the work's authorship and initial publication in this journal.

Authors are permitted and encouraged to post links to their work online (e.g., in institutional repositories or on their website) prior to and during the submission process, as it can lead to productive exchanges, as well as earlier and greater citation of published work. 